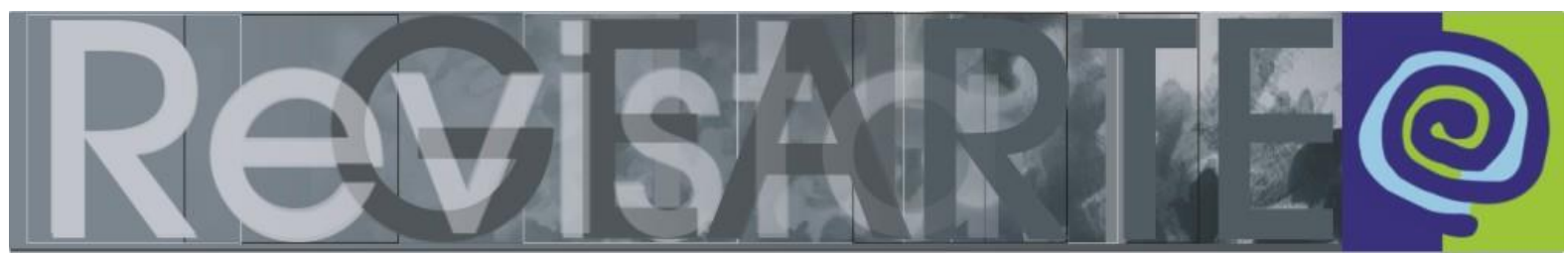

e-ISSN 2357-9854

\title{
Abordagens triangulares: reflexões sobre a aprendizagem triangular da arte
}

\author{
José Minerini Neto (Pesquisador Independente)
}

RESUMO - Abordagens triangulares: reflexões sobre a aprendizagem triangular da arte - Este artigo apresenta reflexões a respeito das muitas concepções sobre a Abordagem Triangular para o ensino da Arte, tratadas aqui no plural, como Abordagens Triangulares. Sistematizada e várias vezes revisada por Ana Mae Barbosa, tem sua história passada a limpo em artigo de Fernando Antônio Gonçalves de Azevedo. Tem nas concepções de teoria aberta e de prática reflexiva os fundamentos norteadores para analisar a problemática das abordagens triangulares, destacando como problema analisado, a releitura de obras de arte no ensino e na aprendizagem da Arte.

PALAVRAS-CHAVE

Abordagens Triangulares. Releitura. Arte. Educação.

ABSTRACT - Triangular approaches: reflections on the triangular learning of art - This article presents reflections about many conceptions about Triangular Approach to teach art, treated here as plural, Triangular Approaches. Systematized and repeatedly revised by Ana Mae Barbosa, has its history cleaned in an article by Fernando Antônio Gonçalves de Azevedo. It has in the conceptions of open theory and reflective practice the guiding principles for analyzing a problematic of triangular approaches, highlighting rereading of art works as a problem analyzed without teaching and learning art.

\section{KEYWORDS}

Triangular Approach. Reread. Art. Education.

Ver, ler, fazeragain and again. Arnaud Reid

Ana Mae Barbosa organizou e mediou em 2015 uma mesa no XXV Congresso da Federação de Arte Educadores do Brasil (CONFAEB) chamada "História das Ideias e Práticas do Ensino da Arte no Brasil", a qual tive a felicidade de dividir com meu querido amigo Fernando Antônio Gonçalves de Azevedo. Ana Mae nos convidou e nos apresentou reiterando que organizou duas mesas ${ }^{1}$ nesse congresso apenas com pesquisadores homens, reafirmando que sua condição pós-feminista não é excludente nem restritiva.

Eu apresentei a trajetória de Wolfgang Pfeiffer na Bienal de São Paulo entre a História da Arte e a Educação. Fernando, por sua vez, fez uma linda apresentação

1 Ana Mae pretendeu com essas mesas realizadas em Fortaleza fundar nos CONFAEBS um núcleo de História do Ensino da Arte. A outra chamava-se História é Interpretação e foi composta por Sidiney Peterson Ferreira de Lima e José Roberto Peres. 
referente à Abordagem Triangular. Entretanto, foi seu artigo que despertou em mim uma inquietação acalentada há anos: a mudança da denominação Proposta Triangular para Abordagem Triangular no Ensino e na Aprendizagem da Arte.

Essa inquietação surgiu quando organizei em 2011 na Universidade Anhembi Morumbi em São Paulo, junto a Ana Mae em colaboração com Adriana Valese e Jofre Silva, o lançamento do livro "Abordagem Triangular no ensino das artes e culturas visuais", quando lá coordenei a graduação em Artes Visuais e Novas Mídias. Este livro, organizado por Ana Mae e Fernanda Pereira da Cunha (2010), resultou de uma pesquisa feita por elas para perceber como os professores estavam lidando com a Proposta Triangular vinte anos depois de publicada no livro "A imagem no ensino da arte" (BARBOSA, 1991) sob a alcunha de Metodologia Triangular para o ensino da arte, e percebi que este livro é composto por várias abordagens sobre a Proposta Triangular.

Originalmente, chamada metodologia e:

[...] usada no Museu de Arte Contemporânea da Universidade de São Paulo integra a história da arte, o fazer artístico, e a leitura da obra de arte. Esta leitura envolve análise crítica da materialidade da obra e princípios estéticos ou semiológicos, ou gestálticos ou iconográficos (BARBOSA, 1991, p. 37).

Desde então, a própria Ana Mae aperfeiçoou o que ela mesma sistematizou. No livro "Tópicos utópicos", publicado em 1998, ela fez a seguinte correção:

Foi no esforço dialogal entre o discurso pós-moderno global e o processo consciente de diferenciação cultural também pós-moderno que, no ensino da arte, surgiu a abordagem que ficou conhecida no Brasil como Metodologia Triangular, uma designação infeliz, mas uma ação reconstrutora. Sistematizada no Museu de Arte Contemporânea da USP (87/93), a Triangulação PósColonialista do Ensino da Arte no Brasil foi apelidada de "metodologia" pelos professores. Culpo-me por ter aceitado o apelido e usado a expressão Metodologia Triangular em meu livro $A$ imagem no Ensino da Arte. Hoje, depois de anos de experimentação, estou convencida de que metodologia é construção de cada professor em sua sala de aula e gostaria de ver a expressão Proposta Triangular substituir a prepotente designação Metodologia Triangular. Em arte e em educação, problemas semânticos nunca são apenas semânticos, mas envolvem conceituação (BARBOSA, 1998, p. 33).

No mesmo texto do qual retirei essa citação, Ana Mae alterou o eixo História da Arte da Proposta Triangular para Contextualização. 
É da condição pós-moderna o convívio com pontos de vista ora complementares, ora divergentes, ora incongruentes e não seria diferente com a Aprendizagem Triangular da Arte. Já não me recordo se li ou ouvi Ana Mae afirmar que não tem problema algum em rever ou revisar o que já fez, e isso é pertinente à sua postura e à produção pós-modernista, contexto maior em que se insere a Aprendizagem triangular da arte.

A multiplicidade de termos decorrentes dessa triangulação não se resume aos eixos que a estruturam e muito menos a três. Pensemos na indefinição da terminologia que define o profissional do ensino da arte em museus e instituições culturais: monitor, mediador, arte-educador ou educador? Ou então a própria delimitação deste campo profissional: arte educação, arte-educação ou arte/educação? Guilherme Nakashato sobre isso escreveu:

Os termos arte/educação e arte/educadores(as), hoje utilizados com crescente frequência, são denominações em constante mutação e, como sempre, atrelados a fundamentações conceituais. O termo Arte-educação já era utilizado por Noemia Varela (Azevedo, 2008, p. 247) na década de 1950, quando era então Diretora Técnica da Escolinha de Arte do Brasil. Já o terno arte/educação com barra vem sendo aventado desde meados de 2002 (Frange, 2002, p. 45), por sugestão da pesquisadora Lucia Pimentel com base na linguagem do computador, no intuito de indicar uma relação de pertencimento entre educação e arte (Barbosa, 2005, p. 21). Segundo Ana Mae Barbosa, "Arte/educação é a mediação entre arte e público e o ensino da Arte é compromisso com a continuidade e/ou com currículo [...]. (NAKASHATO, 2012, p. 15).

Possivelmente, e, ao menos, pelo mesmo motivo (ser a aprendizagem triangular pós-moderna) é que os três eixos que a compõem - fazer, contextualizar e ler arte - mudaram nos Parâmetros Curriculares Nacionais (PCN): Arte(BRASIL, 1997) para fazer, fruir e investigar arte. Vamos comparar o texto original sobre os três eixos da Proposta Triangular quando ainda tratava da História da Arte, em 1991, com o que foi publicado nos PCNs, em 1997.

Ana Mae Barbosa escreveu:

Um currículo que interligasse o fazer artístico, a história da arte e a análise da obra de arte estaria se organizando de maneira que a criança, suas necessidades, seus interesses e seu desenvolvimento estariam sendo respeitados, e ao mesmo tempo, estaria sendo respeitada a matéria a ser aprendida, seus valores, sua estrutura e sua contribuição específica para a cultura (BARBOSA, 1991, p. 35). 
Os PCNs Arte, por sua vez, assim descrevem:

A aprendizagem da arte envolve distintos âmbitos de experiência para abarcar o conhecimento artístico:

- a experiência de fazer formas artísticas incluindo tudo que entra em jogo nessa ação criadora: recursos pessoais, habilidades, pesquisa de materiais e técnicas, a relação entre perceber, imaginar e realizar um trabalho de arte;

- a experiência de fruir formas artísticas, utilizando informações e qualidades perceptivas e imaginativas para estabelecer um contato, uma conversa em que as formas signifiquem coisas diferentes para cada pessoa;

- a experiência de investigar sobre a arte como objetivo de conhecimento, no qual importam dados sobre a cultura em que o trabalho artístico foi realizado, a história da arte e os elementos e princípios formais que constituem a produção artística, tanto de artistas quanto dos próprios alunos (BRASIL, 1997, p. 31).

\section{Maria Helena Wagner Rossi analisou detalhadamente os PCNs e constatou} neles que:

[...] é utilizada a expressão 'apreciação significativa' para referir-se a ações como: convivência, contato sensível, observação, percepção, reconhecimento e experimentação de leitura de elementos da arte. No entanto, o termo priorizado é fruição: 'o conjunto de conteúdos está articulado dentro do contexto de ensino e aprendizagem em três eixos norteadores: a produção, a fruição e a reflexão'. Mais adiante, diz o documento: 'a fruição refere-se à apreciação significativa de arte e do universo a ela relacionado. Tal ação contempla a fruição da produção dos alunos e da produção históricosocial em sua diversidade' (ROSSI, 2003, p. 19).

Como visto, nem mesmo os PCNs abordam essa questão de um único modo:

[...] o termo leitura pode ser confundido com apreciação, fruição, percepção, recepção, acesso, apreensão, compreensão, atribuição de sentidos. Todos servem para denotar o processo que o leitor vive na relação com a obra/imagem, seja na interatividade, na pintura, no museu ou na sala de aula, onde, atualmente, milhares de alunos estão a olhar para as reproduções de obras de arte que os professores estão trazendo para as atividades de leitura (ROSSI, 2003, p. 19).

Ana Mae tem plena consciência de que a "[...] Abordagem Triangular é aberta a reinterpretações e reorganizações, talvez por isso tenha gerado tantos equívocos, mas também gerou interpretações que enriqueceram, ampliaram e explicitaram [...]" (BARBOSA; CUNHA, 2010, p. 11) diversas abordagens e não apenas uma abordagem sobre a Proposta Triangular. Eis uma questão que aponto no título do livro composto por várias Abordagens Triangulares resultantes da pesquisa organizada e publicada por ela e Fernanda Pereira da Cunha em 2011. 
Tenho ouvido pelos corredores de encontros e congressos de arte/educação pesquisadores e professores corrigindo uns aos outros quando alguém se refere à Proposta Triangular e não à Abordagem Triangular. É justamente essa flexibilidade de interpretações e abordagens que me encorajou a escrever esse artigo e a entender que quem é aberta é a Proposta Triangular, cabendo a cada educador fazer a(s) sua(s) abordagem(ns), explicitando, com isso, a complexa maturidade que atingiu a Proposta Triangular, embora Ana Mae eleja o título Abordagem Triangular "[...]porque metodologia quem faz é o professor e proposta é uma palavra desgastada pelas mil e uma que são despejadas, à guisa de guias curriculares, pelos poderes hierárquicos em cima da cabeça dos professores" (BARBOSA; CUNHA, 2010, p. 11).

$\mathrm{O}$ artigo que Fernando Azevedo publicou nos anais do XXV CONFAEB em Fortaleza, chamado "O aqui e agora já é história" contribui imensamente com a história do ensino pós-moderno da Arte no Brasil ao passar a limpo essa história, especificamente no diz respeito ao que foi sistematizado e aprimorado por Ana Mae desde a Metodologia Triangular até a Abordagem Triangular, como se chama até o momento em que aqui escrevo. Assim como Ana Mae, Fernando de imediato deixa claro em seu artigo que a Abordagem Triangular é entendida como teoria aberta:

[...] pois sendo dialógica, vem ao longo de sua história, mobilizando em seus intérpretes o gesto de recriar. Não se apresenta, portanto, como teoria fechada, sendo muito mais um portal, que gera diferentes interpretações/praxis, por isso se distancia da compreensão de método para ser aplicado - sua complexidade exige a reinvenção (AZEVEDO, 2015, p. 172).

Ele perpassa a abertura dessa teoria, confirmada pela sua própria história:

[...] inicialmente denominada de Metodologia Triangular (1991), depois da primeira revisão nomeada de Proposta Triangular (1998), em ambas a metáfora do triângulo está muito presente, enquanto nas revisões mais recentes (a terceira e quarta) a metáfora sugerida por Ana Mae Barbosa para a AT é o ziguezague (AZEVEDO, 2015, p. 175).

Paulo Freire indica como momento fundamental na formação e atuação docente a reflexão crítica sobre a prática, pois:

É pensando criticamente a prática de hoje ou de ontem que se pode melhorar a próxima prática. O próprio discurso teórico, necessário à reflexão crítica, tem de ser de tal modo concreto que quase se confunda com a prática. O seu "distanciamento" epistemológico da prática enquanto objeto de sua análise, deve dela "aproximá-lo" ao máximo. Quanto melhor faça esta operação tanto 
mais inteligência ganha da prática em análise e maior comunicabilidade exerce em torno da superação da ingenuidade pela rigorosidade. Por outro lado, quanto mais me assumo como estou sendo e percebo a ou as razões de ser de porque estou sendo assim, mais me torno capaz de mudar, de promover-me, no caso, do estado de curiosidade ingênua para 0 de curiosidade epistemológica (FREIRE, 1996, p. 39).

Sou autor de materiais didáticos de Arte com circulação nacional. Por conta disso venho visitando professores nas mais diversas regiões do país e, refletindo criticamente sobre a minha prática docente e a de tantos outros professores que encontro trabalhando com o ensino triangular da arte presente nos materiais que escrevo ou coordeno, que são muitas as abordagens triangulares, tanto para o bem quanto para o mal.

Indiscutivelmente, uma das abordagens triangulares mais polêmicas é a calcada na releitura, que agora, além de estar na prática de vários professores, existe (ao menos) uma geração de estudantes formada por esses professores que associam sua formação artística escolar à releitura. A releitura tem aspectos positivos na pósmodernidade, pois muitos artistas revisitaram e continuam revisitando obras de arte do passado e trazendo-as para novos contextos e leituras, apresentados nas obras de arte. Entretanto, a releitura vem sendo muitas vezes banalizada na arte/educação (e na Proposta Triangular) como cópia acrítica e não inventiva de obras de arte.

Ao perceber esse novo e vacilante passo da releitura, disse pessoalmente a Ana Mae que a única pessoa que poderia corrigir esse desvio seria ela, que me respondeu: "Essa maldita releitura. Não tenho mais saco para isso!" (MINERINI NETO, 2015).

Se ela não tem, eu tenho. Compartilhei em 2010 uma mesa com Ana Amália Barbosa em evento organizado por ela e Karen Kinips na Casa das Rosas em São Paulo onde tratamos da releitura. Ana Amália Barbosa questiona:

E o fazer? Como ficou o fazer artístico nessa nova abordagem do ensino da arte? Ficou sendo a tal da releitura, mas de onde veio isso? Quem inventou? Conversei com inúmeras pessoas que trabalham com releitura, professores/as de sala de aula, e perguntei-Ihes de onde vinha essa tal de releitura. Todos me disseram que era da abordagem triangular. Li e reli o livro A imagem no ensino da arte [...] com a intenção de encontrar um momento em que ela falasse dessa tal releitura. Não encontrei no texto, mas nas legendas dos desenhos das crianças. Conversando com a própria Ana Mae 
sobre a origem do termo releitura, ela me disse que provavelmente da prática, do trabalho diário no museu. (MAC/USP) (BARBOSA, 2005, p. 144).

Ana Mae chegou a mesma conclusão e escreveu sobre as abordagens equivocadas com releitura na apresentação da $8^{a}$ edição do livro "A imagem no ensino da arte”, publicada em 2010. "Proposta ou Abordagem Triangular: uma breve revisão" é o título do texto de apresentação desta edição, no qual Ana Mae destaca que:

Os principais enganos de interpretação da Abordagem/Proposta Triangular não encontrei em teses nem dissertações, mas na prática de professores de Arte ou em mal-intencionadas formulações de caráter destrutivo. Trata-se da identificação da Abordagem/Proposta Triangular com a releitura e do uso da releitura como cópia. No texto deste livro (A imagem no ensino da arte), desde a primeira edição, não falo nem uma vez em RELEITURA. Essa palavra aparecia nas edições anteriores a estas, somente nas legendas das imagens produzidas pelas crianças. Professores que confundem Abordagem Triangular com releitura não leram o livro, apenas as legendas das imagens. Para demonstrar meu repúdio à ideia de que receito a releitura, substituí na presente edição (8a $)$ a palavra por interpretação (BARBOSA, 2010a, p. XXIX).

E foi o que Ana Mae Barbosa fez ao retirar, a partir da $8^{a}$ edição de "A imagem no ensino da arte", a palavra releitura das legendas das imagens.

Ana Amália continuou a enfrentar essa questão:

O que quer dizer releitura? Reler, ler novamente, dar novo significado, reinterpretar, pensara mais uma vez. Mais uma vez fui levada a refletir sobre minha experiência. Sou artista plástica e trabalho muito com apropriação e citação, algo muito próprio de nossa contemporaneidade pós-moderna. Aproprio-me de imagens da História da Arte e incluo-as em minha obra, ou seja, tiro a imagem de seu local de origem e a utilizo para construir outra imagem. Também cito muito em meu trabalho, cito artistas de que gosto, cito situações e movimentos da História da Arte (BARBOSA, 2010a, p. XXIX).

Além de compreender a releitura como apropriação e citação, Ana Amália explica a diferença entre ambas:

Quando cito, não existe referência direta. Posso utilizar o modo de trabalhar, da cor mais comum do artista ou da obra que estou citando. No entanto, quando me aproprio da imagem, ela está contida em meu trabalho, inteira ou desconstruída, mas está presente. Uma das coisas mais importantes que aprendi com meu trabalho é que nunca penso em uma obra só, um artista só. Faço relações o tempo todo, inclusive do que vejo na realidade com o que vejo no mundo da arte. Isso tudo é releitura. É olhar o mundo ao nosso redor e criar a partir de tantas coisas que vemos no mundo, na arte, na TV... enfim tudo aquilo que nossa retina registra pode ser usado (BARBOSA, 2005, p. 145). 
Ana Mae acrescenta a essa discussão a questão da reelaboração na arte contemporânea, na qual "[...] o tráfico de imagens é explícito. Na Pop Art, trata-se de uma reelaboração de significado pelo uso de uma retórica, diferente da retórica usada na primeira geração da imagem, de forma diferente dos períodos anteriores o artista pop usa a imagem industrializada" (BARBOSA, 1998, p. 66).

Antes da releitura virar modismo entre arte/educadores, a partir da década de 1990,Sérgio Paulo Rouanet indicou que:

[...] a arte pós-moderna estabelece com a história uma relação sui generis. Esgotada sua capacidade de criação, o artista pós-moderno é forçado a voltar-se para o passado e recorre ao pastiche de obras anteriores. O artista moderno usava a paródia, como recurso cômico ou satírico [...], mas a paródia supõe a existência de uma norma linguística com relação à qual o estilo que está sendo parodiado pode ser compreendido em sua singularidade, criticado, ridicularizado. Num mundo em que não há mais uma norma hegemônica, e sim mil estilos concorrentes, a imitação não se dá sobre o pano de fundo de um estilo padronizado e, portanto, não tem uma intenção ulterior, satírica ou cômica. É o pastiche, a imitação pela imitação (ROUANET, 1987, p. 249-250).

Ele chega a essa conclusão lendo vários teóricos da pós-modernidade (especialmente, Jean-François Lyotard, Fredric Jameson, Jean Baudrillard e Charles Jencks) e analisando a arte dos anos 80 do século passado.

Baudrillard, por sua vez, destaca nas imagens pós-modernas a irreverência dissimulada: "Dissimular é fingir não ter o que se tem. Simular é fingir ter o que não se tem. O primeiro refere-se a uma presença, o segundo a uma ausência. Mas é mais complicado, pois simular não é fingir [...]" (BAUDRILLARD, 1991, p. 9). Frente a essa complexidade, ele diferencia três categorias de simulacro:

[...] - simulacros naturais, naturalistas, baseados na imagem, na imitação e no fingimento, harmoniosos, otimistas e que visam a restituição ou a instituição ideal de uma natureza à imagem de Deus,

- simulacros produtivos, produtivistas, baseados na energia, na força, na sua materialização pela máquina e em todo o sistema da produção - objeto prometiano de uma mundialização e de uma expansão contínua, de uma libertação de energia indefinida (o desejo faz parte das utopias relativas a esta categoria de simulacros),

- simulacros de simulação, baseados na informação, no modelo, no jogo cibernético - operacionalidade total, hiper-realidade, objeto de controle total (BAUDRILLARD, 1991, p. 151). 
Incontáveis as vezes que ouvi professores referirem-se à Proposta Triangular como o trabalho da releitura, certamente sem nenhuma consciência sobre o complexo trânsito estabelecido entre citações, apropriações, reelaborações, pastiches e simulacros. Analice Dutra Pillar indica o que seria relevante na releitura:

Há uma grande distância entre releitura e cópia. A cópia diz respeito ao aprimoramento técnico, sem transformação, sem interpretação, sem criação. Já na releitura há transformação, interpretação, criação com base num referencial num texto visual que pode estar explícito ou implícito na obra final. Aqui o que se busca é a criação e não a reprodução da imagem (PILLAR, 2003, p. 19).

Como se vê, releitura é, assim como o ensino triangular da arte, uma questão da pós-modernidade, e que é possível fazê-la como aprendizagem artística significativa nas escolas e não mera reprodução tecnicista esvaziada de novos sentidos.

Após minha fala e de Fernando no XXV CONFAEB em 2015, Ana Mae, a propositora e mediadora dessa mesa, que, segundo ela, inaugurou o núcleo de História do Ensino da Arte no CONFAEB, abriu perguntas para a plateia. Não perdi a oportunidade e questionei Fernando sobre o que seria teoria aberta: a Proposta ou a Abordagem Triangular? Como exemplo de minha indagação, destaquei que a releitura era um tipo de abordagem sobre a Proposta Triangular. Ruim, mas era. E é!

A plateia estava lotada e tomada por célebres arte/educadores de todo o Brasil, membros da FAEB - Federação de Arte Educadores do Brasil, artistas (destaque para a presença de Roberto Galvão), professores e estudantes de Arte de Fortaleza.

Rejane Coutinho estava na plateia e foi questionada por Ana Mae se ela ainda percebia professores trabalhando releitura como cópia. Ao longe, e com um sorriso ligeiramente constrangido, Rejane acenou positivamente com a cabeça.

Este artigo é a minha resposta à pergunta que eu mesmo fiz, que, destaco, não tem nenhuma intenção de confrontar as revisões que Ana Mae Barbosa vem fazendo sobre o que ela mesma sistematizou para o ensino e a aprendizagem da arte, mas sim, uma tentativa de contribuir com as práticas reflexivas sobre a arte/educação. Cada professor faz a sua abordagem triangular, daí entender que é possível realizar 
muitas abordagens sobre a Proposta Triangular, às vezes feitas de diversos modos por um mesmo professor.

\section{Referências}

AZEVEDO, Fernando. O aqui e agora já é história. In: CONGRESSO NACIONAL DA FEDERAÇÃO DE ARTE/EDUCADORES DO BRASIL, 25, 2015, Fortaleza. Anais... Fortaleza: FAEB/IFCE, 2015.

BARBOSA, Ana Mae. A imagem no ensino da arte: anos 80 e novos tempos. 1a. ed. São Paulo: Perspectiva, 1991.

BARBOSA, Ana Mae. Tópicos utópicos. Belo Horizonte: C/ Arte, 1998.

BARBOSA, Ana Mae. Arte/educação contemporânea: consonâncias internacionais. São Paulo: Cortez, 2005.

BARBOSA, Ana Amália. Releitura, citação, apropriação ou o quê? In: BARBOSA, Ana Mae. Arte/educação contemporânea: consonâncias internacionais (Org.). São Paulo: Cortez, 2005.

BARBOSA, Ana Mae; CUNHA, Fernanda Pereira da (Org.). Abordagem Triangular no Ensino das Artes e Culturas Visuais. São Paulo: Cortez, 2010.

BARBOSA, Ana Mae. A imagem no ensino da arte: anos 80 e novos tempos. 8a. ed. São Paulo: Perspectiva, 2010a.

BAUDRILLARD, Jean. Simulacros e simulações. Lisboa: Relógio d'Água, 1991.

BRASIL. Ministério da Educação, Secretaria de Educação Fundamental. Parâmetros Curriculares Nacionais: Arte. Brasília: MEC/SEF, 1997.

FREIRE, Paulo. Pedagogia da autonomia. São Paulo: Paz e Terra, 1996.

MINERINI NETO, José. Depoimento de Ana Mae Barbosa, [2015]. No prelo.

NAKASHATO, Guilherme. A educação não formal como campo do estágio: contribuições na formação inicial do arte/educador. São Paulo: SESI-SP, 2012.

PILLAR, Analice Dutra (Org.). A educação do olhar no ensino das artes. 3a. Porto Alegre: Mediação, 2003.

ROSSI, Maria Helena Wagner. Imagens que falam: leitura da arte na escola. 2a. ed. Porto Alegre: Mediação, 2003.

ROUANET, Sergio Paulo. As razões do Iluminismo. São Paulo: Cia. das Letras, 1987.

\section{José Minerini Neto}

Doutor em Artes Visuais pela ECA/USP com período sanduíche no Teachers College/Columbia University em Nova York; Mestre em Estética e História da Arte com Licenciatura Plena em Educação Artística. É coordenador, professor e autor de material educativo na área de Arte/Ens. Fundamental da rede particular de São Paulo e editor da revista eletrônica AEOL - Arteducação Online. Tem experiência na área de Arte com ênfase em Arte/educação, História da Arte Moderna e Contemporânea, Arte e Política e História do Ensino da Arte. Sua tese de doutorado organizou a partir de documentos primários a história da "Educação nas Bienais de Arte de São Paulo" entre 1951 e 2011. Foi contemplado com Bolsa Sanduíche da CAPES - Coordenação de Aperfeiçoamento de Pessoal de Ensino Superior para realizar a pesquisa "John Dewey: Progressive Education and Democracy in Museums", na qual analisou propostas educacionais em trinta e dois museus situados em Boston, Filadélfia, Nova York e Washington. A dissertação de mestrado em Estética e História da Arte voltou-se à obra de Regina Silveira entre os anos de formação e o início de seu mestrado, período que engloba a Ditadura Militar no Brasil e antecede as perspectivas e sombras que a tornaram célebre. Membro fundador do coletivo Arteducação Produções, participou da fundação do Programa Educativo do CCBB _ SP - Centro 
Cultural Banco do Brasil São Paulo, no qual participou da formulação e desenvolvimento das primeiras oficinas educativas, assim como da organização e realização de materiais educativos e encontros para educadores nesta instituição e na Caixa Cultural de São Paulo. Trabalha também com direção de Arte e cenografia para teatro e eventos corporativos. Tem produção artística em desenho, pintura, fotografia, escultura e performance. Coordenou curso de graduação universitária em Artes e Novas Mídias. Atualmente vem participando da formação de equipes educacionais em diversas instituições culturais. Como pesquisador independente, realiza pesquisas sobre a recepção espontânea do professor em museus de Arte.

E-mail: jminerini@gmail.com

Currículo: http://lattes.cnpq.br/6031242208088301

Recebido em 15 de março de 2017 Aceito em 23 de julho de 2017 